\title{
Black is the new black
}

\author{
Dawn S. Hui, MD, and Richard Lee, MD, MBA
}

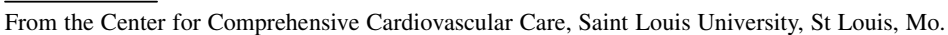

Disclosures: Authors have nothing to disclose with regard to commercial support.

Received for publication Aug 1, 2017; accepted for publication Aug 8, 2017; available ahead of print Sept 13, 2017.

Address for reprints: Richard Lee, MD, MBA, Center for Comprehensive Cardiovascular Care, Saint Louis University, 3635 Vista Ave, DT 13F, St Louis, MO 63110 (E-mail: rlee@slu.edu).

J Thorac Cardiovasc Surg 2018;155:618-9

$0022-5223 / \$ 36.00$

Copyright (C) 2017 Published by Elsevier Inc. on behalf of The American Association for Thoracic Surgery http://dx.doi.org/10.1016/j.jtcvs.2017.08.010

Since the cut-and-sew Cox-maze (CM) operation was first described, there have been numerous developments in surgical ablation for atrial fibrillation (AF), including surgical technique, ablative technologies, postablation monitoring, and outcome reporting. Heterogeneity of clinical practice has made it difficult to draw conclusions across studies, most of which are retrospective. Although controversies abound, such as the optimal lesion set, ${ }^{1}$ biatrial versus right atrial, ${ }^{2}$ management of the left atrial appendage (LAA), ${ }^{3}$ and postoperative antiarrhythmic management, ${ }^{4}$ there is sufficient evidence such that concomitant ablation at the time of mitral valve surgery is a class I, level of evidence A recommendation. ${ }^{5}$

In this issue, Wang and colleagues ${ }^{6}$ present a randomized trial comparing concomitant ablation with a CM-III to no ablation in patients with AF undergoing surgery for rheumatic mitral valve disease. Their results once again demonstrate that the CM-III is safe, efficacious, and offers stroke reduction and survival benefits. This is not news, because many studies have already demonstrated the safety and efficacy of CM-III in rheumatic patients, ${ }^{7-11}$ some with contemporary postoperative monitoring utilizing Holter ${ }^{8,9}$ and with even longer follow-up of anywhere from 3 to 9 years. Given the prior evidence, then, what was the rationale for the design of the study by Wang and colleagues ${ }^{6}$ ? The authors offer 2 reasons: their prior retrospective study of a CM-IV approach with freedom from AF of $76 \%$ at 1 year and $67 \%$ at 5 years and recent data showing a $40 \%$ concomitant ablation rate in eligible patients. Based on this, they theorize that lack of confidence in energybased ablation is what drives the low rate of concomitant ablation. In fact, when considering mitral patients, database rates of concomitant ablation are higher than other cardiac lesions, at $52 \%$ overall $^{12}$ and as high as $61 \%$ in mitral repairs. ${ }^{13}$ Nevertheless, the fact remains that there is room for improvement.

Drilling down into the results, the primary end point was composite freedom from death or stroke. Actuarial survival analysis showed no mortality difference at 1 year. This suggests that the composite end point was likely driven by a difference in stroke, which was substantial $(12.3 \%$ vs $0 \%)$.

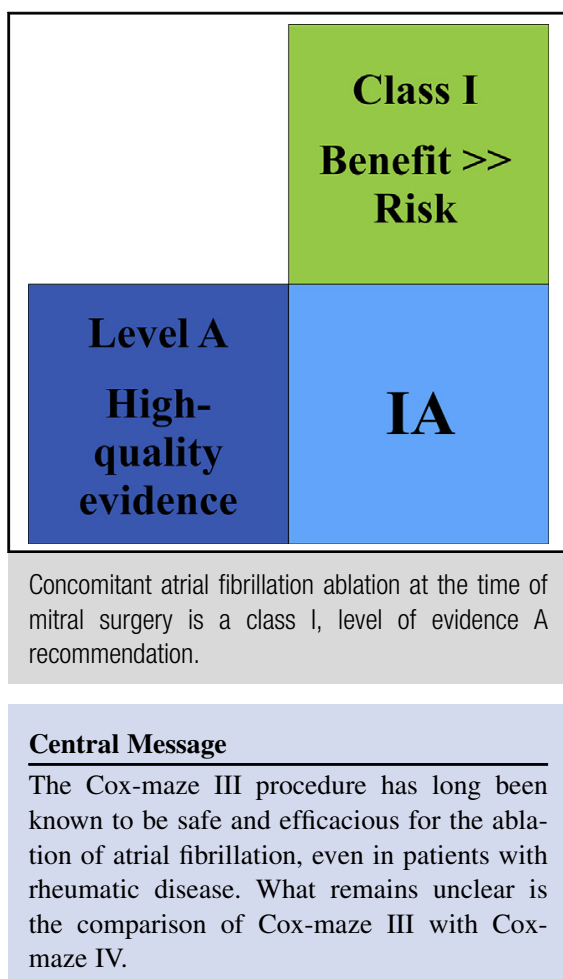

See Article page 608.

With $90 \%$ of patients undergoing mechanical valve replacements, this is curious. Would this magnitude of stroke benefit of a maze operation be expected in patients who were reportedly fully anticoagulated? Notably, management of the LAA differed between groups, with the CMIII group undergoing excision and nonmaze patients undergoing ligation or internal suture, with excision reserved only for the presence of thrombus. Lee and colleagues ${ }^{14}$ previously demonstrated a difference in late neurologic events according to technique, LAA excision being superior $(0.2 \%$ vs $1.3 \%$ annualized). If one were to extrapolate, at 1 year follow-up the magnitude of difference in the study by Wang and colleagues ${ }^{6}$ is roughly double what would be expected. In light of a predominantly young population with mechanical valves, this raises more questions about anticoagulation management than about maze procedure efficacy for stroke reduction.

To move the needle on concomitant AF ablation, the real comparison should not be CM-III versus no ablation, but rather CM-III versus CM-IV. In fact, some data do exist. Baek and colleageus ${ }^{8}$ compared CM-III with cryomaze, finding equivalent freedom from $\mathrm{AF}$ at 2 years and event- 
free survival at 4 years. Using radiofrequency ablation techniques, Guang and colleagues ${ }^{11}$ demonstrated $77 \%$ freedom from AF rate at 3 years (with the caveat that a homemade ablation device and electrocardiogram-only postoperative monitoring were used). There is technique and judgment in applying CM-IV lesions as well. Wang and colleagues ${ }^{6}$ may do well to re-examine their CM-IV operation and outcomes in light of this.

Some reference a hesitation to performing CM-III due to its purported risk and complexity. It is neither a casual operation-it requires technical skill and experience-nor an obsolete operation, with Ad and colleagues ${ }^{15}$ recently reporting outcomes with concomitant aortic valve replacement and coronary artery bypass graft. Although the authors should be commended for practicing and promoting the gold standard, this study skirts an ethical line. It is true that there is a paucity of randomized trials on $\mathrm{AF}$ ablation, but the guidelines are clear: concomitant $\mathrm{AF}$ ablation at the time of mitral valve surgery is a class I recommendation with level of evidence A. Sixty-five patients in this study were denied this guideline adherence and consequently the short- and long-term benefits of surgical ablation. This experiment need not, and should not, be repeated. Future endeavors should not sacrifice rigor of treatment and patient care purely for scientific rigor.

\section{References}

1. Gillinov AM, Bakaeen F, McCarthy PM, Blackstone EH, Rajeswaran J, Pettersson G, et al. Surgery for paroxysmal atrial fibrillation in the setting of mitral valve disease: a role for pulmonary vein isolation? Ann Thorac Surg. 2006:81:19-26; discussion 27-8.

2. Churyla A, Iddriss A, Andrei AC, Kruse J, Malaisrie SC, Passman R, et al. Biatrial or left atrial lesion set for ablation during mitral surgery: risks and benefits. Ann Thorac Surg. 2017;103:1858-65.

3. Lee R, Vassallo P, Kruse J, Malaisrie SC, Rigolin V, Andrei AC, et al. A randomized, prospective pilot comparison of 3 atrial appendage elimination techniques: internal ligation, stapled excision, and surgical excision. J Thorac Cardiovasc Surg. 2016;152:1075-80.

4. Ad N, Holmes SD, Shuman DJ, Pritchard G, Miller CE. Amiodarone after surgical ablation for atrial fibrillation: Is it really necessary? A prospective randomized controlled trial. J Thorac Cardiovasc Surg. 2016;151: 798-803.

5. Badhwar V, Rankin JS, Damiano RJ Jr, Gillinov AM, Bakaeen FG, Edgerton JR, et al. The Society of Thoracic Surgeons 2017 clinical practice guidelines for the surgical treatment of atrial fibrillation. Ann Thorac Surg. 2017;103:329-41.

6. Wang H, Han J, Wang Z, Yin Z, Liu Z, Jin Y, et al. A prospective randomized trial of the cut-and-sew maze procedure in patients undergoing surgery for rheumatic mitral valve disease. J Thorac Cardiovasc Surg. 2018;155: 608-17.

7. Lee JW, Park NH, Choo SJ, Jo MS, Song H, Song MG. Surgical outcome of the maze procedure for atrial fibrillation in mitral valve disease: rheumatic versus degenerative. Ann Thorac Surg. 2003;75:57-61.

8. Baek MJ, Na CY, Oh SS, Lee CH, Kim JH, Seo HJ, et al. Surgical treatment of chronic atrial fibrillation combined with rheumatic mitral valve disease: effects of the cryo-maze procedure and predictors for late recurrence. Eur J Cardiothorac Surg. 2006;30:728-36.

9. Wu M, Zhang S, Dong A, He Z, Chen S, Chen R. Long-term outcomes of maze procedure plus valve replacement in treating rheumatic valve disease resulting in atrial fibrillation. Ann Thorac Surg. 2010;89:1942-9.

10. Kim KC, Cho KR, Kim YJ, Sohn DW, Kim KB. Long-term results of the Coxmaze III procedure for persistent atrial fibrillation associated with rheumatic mitral valve disease: 10-year experience. Eur J Cardiothorac Surg. 2007;31: 261-6.

11. Guang Y, Zhen-Jie C, Yong LW, Tong L, Ying L. Evaluation of clinical treatment of atrial fibrillation associated with rheumatic mitral valve disease by radiofrequency ablation. Eur J Cardiothorac Surg. 2002;21:249-54.

12. Gammie JS, Haddad M, Milford-Beland S, Welke KF, Ferguson TB Jr, O'Brien SM, et al. Atrial fibrillation correction surgery: lessons from the Society of Thoracic Surgeons National Cardiac Database. Ann Thorac Surg. 2008;85: 909-14.

13. Badhwar V, Rankin JS, He X, Jacobs JP, Gammie JS, Furnary AP, et al. The Society of Thoracic Surgeons Mitral Repair/Replacement Composite Score: a report of The Society of Thoracic Surgeons Quality Measurement Task Force. Ann Thorac Surg. 2016;101:2265-71.

14. Lee R, Jivan A, Kruse J, McGee EC Jr, Malaisrie SC, Bernstein R, et al. Late neurologic events after surgery for atrial fibrillation: rare but relevant. Ann Thorac Surg. 2013;95:126-31.

15. Ad N, Henry L, Hunt S, Holmes SD. Do we increase the operative risk by adding the Cox Maze III procedure to aortic valve replacement and coronary artery bypass surgery? J Thorac Cardiovasc Surg. 2012;143:936-44. 